\title{
Preparation and evaluation of the mixtures of sulfonate and phenate as lube oil additives
}

\author{
Amal M. Nassar ${ }^{1}$ Nehal S. Ahmed ${ }^{1} \cdot$ Reham I. El-shazly $^{1} \cdot$ Yasser K. Abd el menem $^{2}$
}

Received: 1 November 2016/Accepted: 26 July 2017/Published online: 8 September 2017

(c) The Author(s) 2017. This article is an open access publication

\begin{abstract}
Lubricating oil additives impart new properties to oil or reinforce desirable properties already possessed by the oil. They are used to prevent sludge and varnish deposits in engines, to inhibit rust and corrosion, and to minimize wear and friction. Detergents, especially basic detergents, contain reserve base that will neutralize the acids, while this decreases the corrosive tendency of the acids formed at high temperatures. Dispersants also disperse sludge formed in engine operated at low temperature. In the present work, neutral, basic, and overbasic calcium salt of sulfurized dodecyl phenol and neutral calcium sulfonate were prepared and evaluated as antioxidant and detergent/dispersants. Also, different metallic mixtures were prepared via mixing dodecyl benzene sulfonic acid and neutral calcium salt of dodecyl phenol in different ratios. Then basic and overbasic of corresponding mixtures were prepared using excess of calcium hydroxide and carbon dioxide. The efficiency of the prepared compounds as detergent/dispersant additives for lubricating oil was investigated. It was found that the prepared additives have excellent power of dispersion and detergency and this efficiency increases by increasing basicity, percentage of calcium salt, and the ratio of dodecyl benzene sulfonic acid in the mixture.
\end{abstract}

Keywords Lubricating oil additives - Basic and overbasic detergents and dispersants - Calcium phenate $\cdot$ Sulfonate

Nehal S. Ahmed

mynehal@yahoo.com

1 Department of Petroleum Applications, Egyptian Petroleum Research Institute, Nasr City, Cairo, Egypt

2 Chemistry Department, Faculty of Science, Menofia University, Shebin el koum, Menofia, Egypt

\section{Introduction}

Automobile lubricants have been used to minimize wear, improve efficiency, and hence prolong the life of an engine. The lubricant additives industry has worked in partnership with the oil and the automotive industries to enhance durability and performance of engine and driveline systems through lubricant design [1]. The lubricating oil must meet specific requirements: it must have an optimal balance of light and heavy oil components to lubricate at high temperature; it should not produce deposits (carbon soot and other) on moving parts, and it should be ashless. In addition, the oil should provide good protection of moving parts at high speed under deceleration of the engine with the throttle closed, when the engine usually suffers from oil starvation [2-5]. The base oil alone cannot provide all the functions required in modern engines. Therefore, additive packages have evolved to play an increasingly important role in the oil formulation [6]. Additives for the future lubricants will be required to maintain oil consumption control over the life of the equipment while providing a high level of thermal stability and enhancing low temperature fluidity. With respect to many applications of lubricating oils, it is desirable that viscosity changes of lubricating oil be relatively small within the temperature change of use and with particular respect to the engine from cold starting up to hot running conditions [7, 8]. The addition of engine oil additives has many purposes. These additives act as defoamers, viscosity improvers, pour-point depressants, antiwear additives, extreme pressure additives, detergents, and dispersants [9]. Detergents are an integral part of any engine oil formulation. Detergents and dispersants constitute $2-15 \%$ of the additives [10]. These compounds keep oil-insoluble combustion by-products in 
suspension and prevent the agglomeration of the oxidation products into solid particles.

Detergents are typically metal salts of organic acids, containing a surface-active polar group which can react with metal surfaces to form a protective film that keeps metal surfaces of an engine clean. In addition to cleaning, detergents also neutralize acidic combustion and oxidation products, thereby, minimizing corrosion, rust, and deposit formation in the engine. Recently, calcium sulfonates have been explored for their antiwear (AW) properties. These detergents keep the metal surfaces of an engine clean, also possess desirable AW, anti-scuffing properties [11-14]; overbased detergents are also known to play a significant role as antiwear, extreme pressure, and friction-reducing additives. Basically, these additives are colloidal dispersions of metal hydroxides, carbonates, or borates stabilized by metallic soaps such as phenates, salicylates, or sulfonates. Metals are usually calcium or magnesium. The polar head of the surfactant (sulfonate) attaches to the metal core (calcium carbonate) while the hydrocarbon tail of hydrophobic nature, such as an oil-soluble alkyl chain, stabilizes the colloidal particle in the non-polar oil medium [15]. The most commonly used detergents are derived from sulfonic acids. Sulfonates have the general formula $\left(\mathrm{RSO}_{3}\right)_{x} \mathrm{M}_{y}$, two types are currently produced: natural sulfonates and synthetic sulfonates. Phenates and phenate sulfides have played an important role as detergent additives for crankcase oil. Alkylphenols and substituted alkylphenols have been utilized for some time as substrates for the preparation of detergents. In the present work, we synthesized neutral, basic, and overbasic calcium salt of sulfurized dodecyl phenol and neutral calcium salt of dodecyl benzene sulfonic acid. Also, different metallic mixtures were prepared via mixing dodecyl benzene sulfonic acid and neutral calcium salt of dodecyl phenol in different ratios. Then basic and overbasic of corresponding mixtures were prepared using excess of calcium hydroxide and carbon dioxide.

\section{Experimental}

\section{Preparation of neutral calcium salt of sulfurized dodecyl phenol}

0.1 mol of dodecyl phenol and $0.05 \mathrm{~mol}$ of calcium hydroxide with $0.15 \mathrm{~mol}$ of sulfur were mixed in four-neck round-bottom flask equipped with a mechanical stirrer, reflux condenser, thermometer, and dropping funnel. The reaction mixture was maintained at temperature $130{ }^{\circ} \mathrm{C}$; $1.5 \mathrm{ml}$ of ethylene glycol was added drop wise along half an hour using dropping funnel till the color converted from yellow to brown, then, dropping funnel is replaced by nitrogen bubbler. The reaction is continued at $130{ }^{\circ} \mathrm{C}$ for an hour, then it is raised to $160{ }^{\circ} \mathrm{C}$ along $1 \mathrm{~h}$. The reaction is placed at this temperature for $2 \mathrm{~h}$, then temperature was raised gradually along an hour to $190{ }^{\circ} \mathrm{C}$ and the reaction was maintained at this point for another $2 \mathrm{~h}$. $(33 \%$ of volume) of white oil is added, then we obtained the product (A) [16].

\section{Basing and overbasing of calcium salt of sulfurized dodecyl phenol}

Sulfurized calcium salt of dodecyl phenol (A) was mixed with $30 \mathrm{~g}$ of toluene, $9.8 \mathrm{~g}$ of methanol, and excess of calcium hydroxide was added by a percent of $1 \mathrm{~mol}$ of calcium phenate to $1 \mathrm{~mol}$ of calcium hydroxide (basic salt) and $1 \mathrm{~mol}$ of calcium phenate to $2.5 \mathrm{~mol}$ of calcium hydroxide (overbasic salt). The mixture was stirred in a three-neck flask. $\mathrm{CO}_{2}$ was inserted with a rate of $50 \mathrm{ml} /$ min. $10 \mathrm{gm}$ of white oil was added as a diluent to faciliate stirring, and after the reaction was completed the solvent was removed using rotary evaporator and at $90{ }^{\circ} \mathrm{C}$ compounds $\left(A_{1}, A_{2}\right)$ were obtained.

\section{Preparation of neutral calcium dodecyl benzene sulfonate}

Neutral calcium dodecyl benzene sulfonate was prepared by mixing $0.2 \mathrm{~mol}$ of dodecyl benzene sulfonic acid with $100 \mathrm{ml}$ of petroleum ether (bp $40-60{ }^{\circ} \mathrm{C}$ ) and $50 \mathrm{ml}$ of light oil as a diluent, then $0.1 \mathrm{~mol}$ of calcium hydroxide was solubilized in $200 \mathrm{ml}$ ethanol. Then solubilized calcium hydroxide was added above the prepared mixture in a three-neck flask equipped with a reflux condenser and thermometer. The reaction mixture is kept refluxing for $2 \mathrm{~h}$ at temperature $40{ }^{\circ} \mathrm{C}$. The solvent was removed using rotary evaporator at temperature $60{ }^{\circ} \mathrm{C}$, and compound (B) was obtained. Basic and overbasic calcium salts of dodecyl benzene sulfonic acid are sparingly soluble in lube oil.

\section{Preparation of different mixtures of neutral sulfurized dodecyl phenate with dodecyl benzene sulfonic acid}

Mixing different ratios of neutral sulfurized dodecyl phenate with dodecyl benzene sulfonic acid and calcium hydroxide dissolved in $200 \mathrm{ml}$ ethanol (0.075: 0.025 : 0.0125, 0.05: 0.05: 0.025, and 0.025: 0.075: 0.0375) moles, respectively, and reflux the mixture for $2 \mathrm{~h}$ at $25^{\circ} \mathrm{C}$, then the solvent was removed by rotary evaporator for an hour at $60-80{ }^{\circ} \mathrm{C}$ to obtain different mixtures $(X, Y$, and $Z$ ). 


\section{Preparation of basic and overbasic mixtures}

The prepared mixtures [mix $(X)$, mix $(Y)$, and mix $(Z)$ ] were mixed with $30 \mathrm{~g}$ of toluene, $9.8 \mathrm{gm}$ of methanol, and excess of calcium hydroxide was added by a percent of $1 \mathrm{~mol}$ of the mixture to $1 \mathrm{~mol}$ of calcium hydroxide (basic salt) and $1 \mathrm{~mol}$ of the mixture to $2.5 \mathrm{~mol}$ of calcium hydroxide (overbasic salt). The mixture was stirred in a three-neck flask. $\mathrm{CO}_{2}$ was inserted with a rate of $50 \mathrm{ml} / \mathrm{min}$ after the completion of the reaction. $10 \mathrm{~g}$ of white oil was added as a diluent. Solvent was removed using rotary evaporator at $90{ }^{\circ} \mathrm{C}$. Compounds $\left[\operatorname{mix}(X)_{1}\right.$, mix $(X)_{2}$, mix $(Y)_{1}$, mix $(Y)_{2}$, mix $(Z)_{1}$, and $\left.\operatorname{mix}(Z)_{2}\right]$ were obtained [17]. The prepared mixtures and their designation are shown in Table 1.

\section{Evaluation of the prepared compounds as lube oil additives}

\section{As antioxidants}

The lube oil samples as well as its blends with $2 \%$ by weight of each of the prepared additives were subjected to severe oxidation condition in the presence of copper and iron strips at $165.5^{\circ} \mathrm{C}$ for $72 \mathrm{~h}$ using the Indiana test method of oxidation [18]. The oxidation stability of the lube oil blends were determined by taking samples at $24 \mathrm{~h}$ intervals to $72 \mathrm{~h}$. These samples were tested for:

1. Variation of viscosity ratio $V / V_{0}$.

The variation of viscosity ratio $\left(V / V_{0}\right)$ has been determined using IP 48/86 method, where:

$V=$ Kinematic viscosity at $40{ }^{\circ} \mathrm{C}$ of sample after oxidation.

$V_{0}=$ Kinematic viscosity at $40{ }^{\circ} \mathrm{C}$ of sample before oxidation.
2. Change in total acid number ( $\Delta \mathrm{TAN})$.

The change has been calculated according to IP $177 / 83$ method, where

$$
\begin{aligned}
\Delta \mathrm{TAN} & =(\text { total acid number of sample after oxidation } \\
& - \text { total acid number of sample before oxidation }) . .
\end{aligned}
$$

3. Optical density using infrared techniques.

The infrared spectra of oxidized oils have been determined in the range of the carbonyl group absorbance (1500-1900 $\left.\mathrm{cm}^{-1}\right)$. The spectra have been superimposed upon that of unoxidized oil. The absorbance (A) has been calculated according to

$A=\log I / I_{0}$,

where $I$ is $\%$ transmittance of the oil after oxidation and $I_{0}$ is the transmittance of the oil before oxidation.

\section{As detergents/dispersants}

1 Spot method [19]

Drops were taken from the samples being oxidized in the Indiana test after $24 \mathrm{~h}$ intervals of oxidation and up to $72 \mathrm{~h}$ to make spots on special filter paper (Durieux 122) and the dispersancy of the samples was measured as follows:

$\%$ Dispersancy $=\frac{\text { Diameter of the black spot }}{\text { Diameter of the total spot }} \times 100$.

The efficiency of dispersants has been classified as follows:

Table 1 The prepared mixtures and their designation

Mixture Designation of mixture

code

$(X)$

$(X)_{1}$

$(X)_{2}$

(Y)

$(Y)_{1}$

$(Y)_{2}$

$(Z)$

$(Z)_{1}$

$(Z)_{2}$
Neutral salt of [0.075 mol of neutral sulfurized dodecyl phenate $(\% \mathrm{~S}=1.5 \%)$ with $0.025 \mathrm{~mol}$ of dodecyl benzene sulfonic acid] Basic salt of $[0.075 \mathrm{~mol}$ of neutral sulfurized dodecyl phenate $(\% \mathrm{~S}=1.5 \%)$ with $0.025 \mathrm{~mol}$ of dodecyl benzene sulfonic acid] Overbasic salt of $[0.075 \mathrm{~mol}$ of neutral sulfurized dodecyl phenate $(\% \mathrm{~S}=1.5 \%)$ with $0.025 \mathrm{~mol}$ of dodecyl benzene sulfonic acid]

Neutral salt of $[0.05 \mathrm{~mol}$ of neutral sulfurized dodecyl phenate $(\% \mathrm{~S}=1.5 \%)$ with $0.05 \mathrm{~mol}$ of dodecyl benzene sulfonic acid] Basic salt of $[0.05 \mathrm{~mol}$ of neutral sulfurized dodecyl phenate $(\% \mathrm{~S}=1.5 \%)$ with $0.05 \mathrm{~mol}$ of dodecyl benzene sulfonic acid] Overbasic salt of [0.05 mol of neutral sulfurized dodecyl phenate $(\% \mathrm{~S}=1.5 \%)$ with 0.05 mol of dodecyl benzene sulfonic acid] Neutral salt of $[0.025 \mathrm{~mol}$ of neutral sulfurized dodecyl phenate $(\% \mathrm{~S}=1.5 \%)$ with $0.075 \mathrm{~mol}$ of dodecyl benzene sulfonic acid] Basic salt of $[0.025 \mathrm{~mol}$ of neutral sulfurized dodecyl phenate $(\% \mathrm{~S}=1.5 \%)$ with $0.075 \mathrm{~mol}$ of dodecyl benzene sulfonic acid] Overbasic salt of $[0.025 \mathrm{~mol}$ of neutral sulfurized dodecyl phenate $(\% \mathrm{~S}=1.5 \%)$ with $0.075 \mathrm{~mol}$ of dodecyl benzene sulfonic acid] 
Up to $30 \%$ : no dispersancy.

30-50\%: medium dispersancy.

50-60\%: good dispersancy.

60-70\%: very good dispersancy.

Above $70 \%$ : excellent dispersancy.

2 Determination of sludge [20]

The essential feature of the method for determining the content of existent sludge is a $1 \mathrm{~h}$ centrifuging operation in $\left(4233_{\mathrm{ECT}}\right.$ laboratory centrifuge) at $3000 \mathrm{rpm}$, with $10 \mathrm{~g}$ of the test oil in the centrifuge tubes. After centrifuging, the clarified oil is decanted off, then $10 \mathrm{ml}$ of isooctane is added as wash liquid to the tube containing the sludge in the form of a cake, and the sample is again centrifuged for $15 \mathrm{~min}$. The operation is repeated until the sludge is washed completely free of oil. The washed sludge, together with the centrifuge tube, is brought to weight in a thermostat at $105{ }^{\circ} \mathrm{C}$ and the amount of sludge is determined by weighing and expressed as a percentage of the original oil sample.

$$
\begin{aligned}
\% & \text { Sludge }=\frac{\text { Weight of sample after centrifuge }}{\text { Weight of sample }} \\
& \times 100 .
\end{aligned}
$$

\section{Determination of potential detergent/dispersant efficiency} (PDDE)

Two factors are necessary to determine DDE

Detergent index This method is based on centrifugation. A suspension was prepared from the base oil containing $1.5 \%$ additive and $2 \%$ carbon black. This suspension was shared by ultrasonic equipment. Afterwards, the blend was diluted with kerosene and the mixture was centrifuged for $30 \mathrm{~min}$. The blend was examined in photometrical equipment at $530 \mathrm{~nm}$. Detergent index (DI) is determined on the basis of the intensity of transmitted light:

$\mathrm{DI}=\left(-I_{1} / I_{0}\right) \times 100$,

where $I_{1}$ is the intensity of the light after transmission through the blend containing carbon black, $I_{0}$ is the intensity of the light transmitted through the blend free of carbon black.

Washing efficiency The washing efficiency (WE) was measured by Zaslavskii's modified method based on thin layer chromatography. The efficiency was evaluated within 0-125 mm. The results of numerous experiments attested that these two methods were suitable to estimate the potential DD efficiency (PDDE, \%) in oil solutions:

$\mathrm{PDDE}=\frac{\mathrm{DI}+\mathrm{WE}}{225} \times 100$,

where DI is the detergent index (\%), WE is the washing efficiency (mm), and 225 is the maximum value of DI $+\mathrm{WE}(\mathrm{DI} \max =100, \mathrm{WE} \max =125)$ [21].

\section{Results and discussion}

\section{Preparation of neutral calcium salt of sulfurized dodecyl phenol}

Neutral sulfurized calcium dodecyl phenate was prepared via reaction of calcium hydroxide with dodecyl phenol and ratio of sulfur (0.15) mole product (A) is illustrated in Scheme 1.

The infrared spectrum of product (A) is given in Fig. 1 which illustrates the following:

- Strength of $\mathrm{OH}$ band decreases in case of the products. This may be due to the presence of little amounts of unreacted reactant.

- Appearance of C-S peak at $729-758 \mathrm{~cm}^{-1}$ in product (A).

- Appearance of $\mathrm{S}-\mathrm{S}$ peak at $557-563 \mathrm{~cm}^{-1}$ in the product (A).

The physico-chemical properties of the compounds prepared are shown in Table 2.

It's obvious from the data given in Table 2, that the experimental and theoretical values of molecular weights are not identical which may be due to the formation of compounds other than the expected compounds as by-products.

The general formulas of these compounds are:<smiles>CCCCCCCc1ccc(C(=O)O)cc1</smiles>

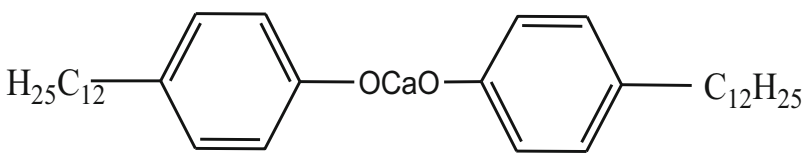




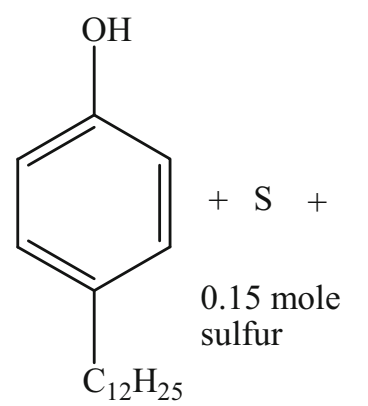

dodecyl phenol 0.1 mole

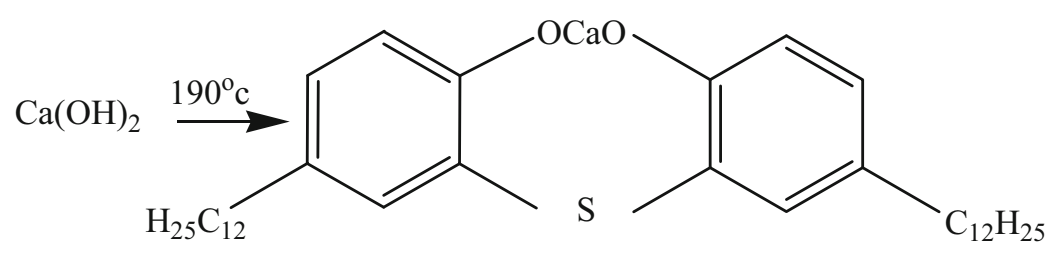

calcium hydroxide 0.05 mole

neutral sulfurized calcium phenate

Scheme 1 Reaction of formation of neutral calcium salt of sulfurized dodecyl phenol

Fig. 1 The infrared spectrum of product (A)

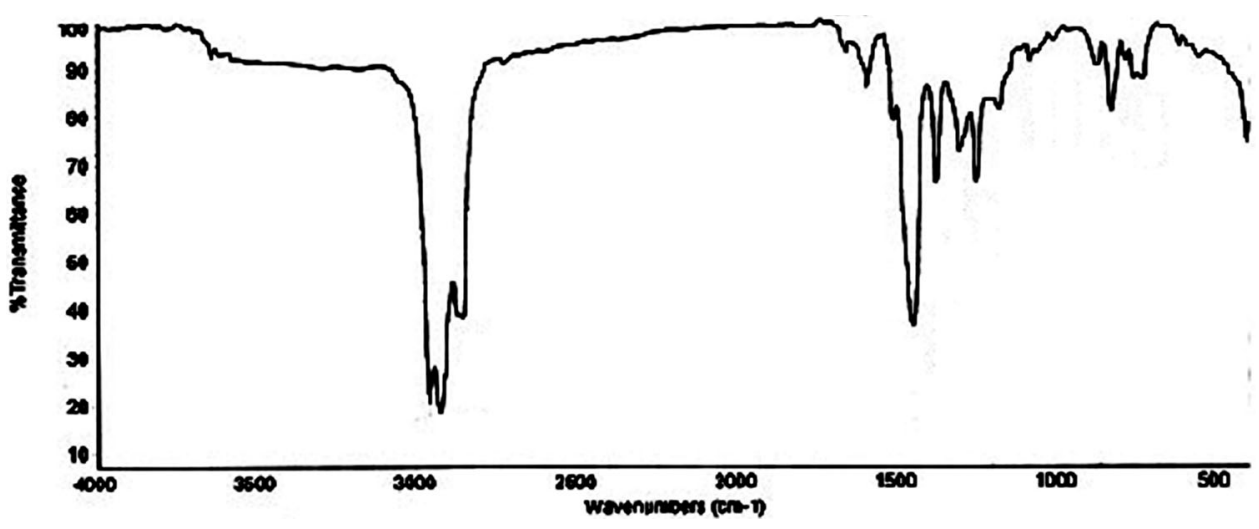

Table 2 The physico-chemical characteristics of the prepared compounds

\begin{tabular}{lc}
\hline Characteristics & Compound (A) \\
\hline Mean M wt & 638.89 \\
Theoretical M wt & 712 \\
TBN & 55 \\
Ca wt\% & 3.5 \\
Sulfur wt\% & 5.586 \\
Carbon wt $\%$ & 75.23 \\
Hydrogen wt\% & 6.73 \\
Oxygen wt $\%$ & 8.954 \\
\hline
\end{tabular}

The experimental formula of the prepared additive $(\mathrm{A})$ is shown as the following: $\left(\mathrm{C}_{40.06} \mathrm{H}_{43} \mathrm{~S}_{1.12} \mathrm{O}_{3.58} \mathrm{Ca}_{0.56}\right)$

\section{Basing and overbasing processes}

Neutral sulfurized calcium salt of dodecyl phenol (A) was used to prepare both basic and overbasic salts. Compounds $\left(\mathrm{A}_{1}, \mathrm{~A}_{2}\right)$ are illustrated in Schemes 2, 3.
The $\mathrm{H}^{1} \mathrm{NMR}$ spectra of compounds $\left(\mathrm{A}, \mathrm{A}_{1}\right.$, and $\left.\mathrm{A}_{2}\right)$ are shown in Figs. 2, 3, and 4, which illustrate the following:

1. A peak appears at 8-9 ppm in case of compounds $(\mathrm{A}$, $\mathrm{A}_{1}, \mathrm{~A}_{2}$ ), which indicates the presence of phenolic $\mathrm{OH}$. The intensity of this peak extremely decreases in case of compounds $\left(\mathrm{A}_{1}\right)$ and $\left(\mathrm{A}_{2}\right)$; this may be due to the presence of percentage of unreacted dodecyl phenol in the preparation of the neutral compound.

2. A peak appears at 0-2 ppm in case of three compounds $\left(\mathrm{A}, \mathrm{A}_{1}\right.$, and $\mathrm{A}_{2}$ ) which indicates the presence of alkyl hydrogen.

3. A peak appears at 6-8 ppm in case of three compounds (A, $A_{1}$, and $A_{2}$ ) which indicates the presence of benzene ring.

4. A peak appears at 3-4 ppm in case of three compounds $\left(\mathrm{A}, \mathrm{A}_{1}\right.$, and $\mathrm{A}_{2}$ ) which indicates the presence of $\mathrm{Ar}-$ $\mathrm{CH}$ group.

The total base number and the percentage of calcium in the prepared basic compound $\mathrm{A}_{1}$ are $140.5,5.84 \%$ but in prepared overbasic compound $\mathrm{A}_{2}$ are $277.9,8.54 \%$ which indicates that an increase in calcium content leads to an increase in the total base number (TBN) of the prepared additives. 
Scheme 2 Reaction of formation of basic calcium dodecyl phenate

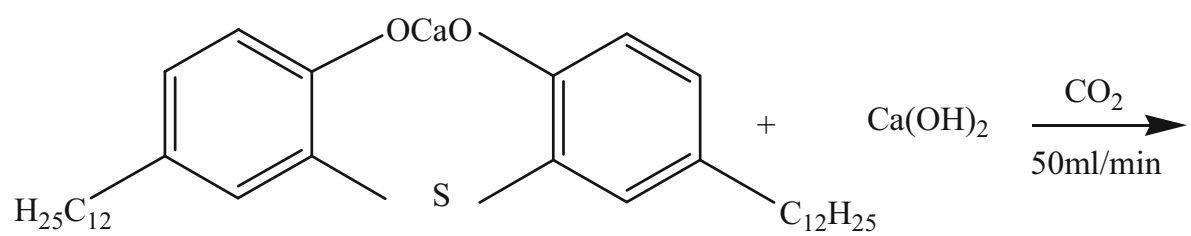

neutral sulfurized calcium dodecyl phenate 0.1 mole

calcium hydroxide 0.1 mole<smiles>CCCCCCc1ccc(OC(=O)O)c(C)c1</smiles>
$\mathrm{S}$<smiles>CCCCCCc1ccc(C(=O)O)c(C)c1</smiles>

Basic sulfurized calcium dodecyl phenate
Scheme 3 Reaction of formation of overbasic calcium dodecyl phenate

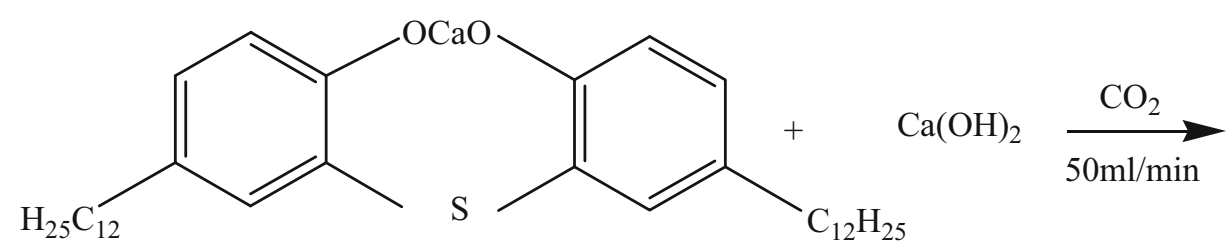

neutral sulfurized calcium dodecyl phenate calcium hydroxide

0.1 mole

0.25 mole

\section{Preparation of neutral calcium dodecyl benzene sulfonate}

Neutral calcium dodecyl benzene sulfonate (B) was prepared by neutralizing dodecyl benzene sulfonic acid with calcium hydroxide, which is illustrated in Scheme 4.
Sulfonates act on the surface of metal parts by creating a protective layer by reaction with the metal surfaces. The total base number and percentage of calcium in the prepared additive B are $60,2.14 \%$.

Basic and overbasic calcium salt of dodecyl benzene sulfonic acid were prepared by addition of an excess of calcium hydroxide with carbon dioxide. 


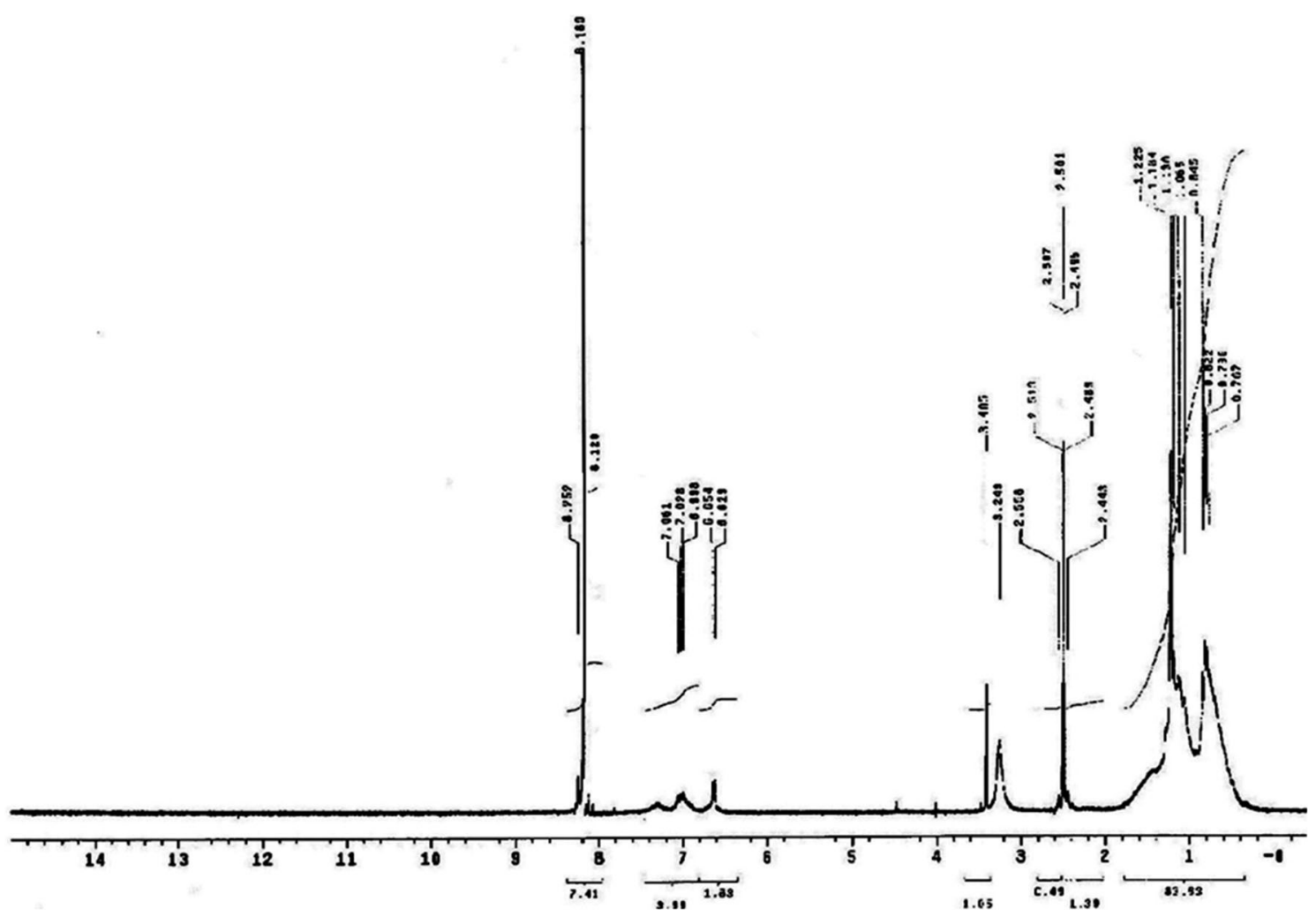

Fig. $2 \mathrm{H}^{1} \mathrm{NMR}$ spectrum of product (A)

Fig. $3 \mathrm{H}^{1} \mathrm{NMR}$ spectrum of product $\left(\mathrm{A}_{1}\right)$

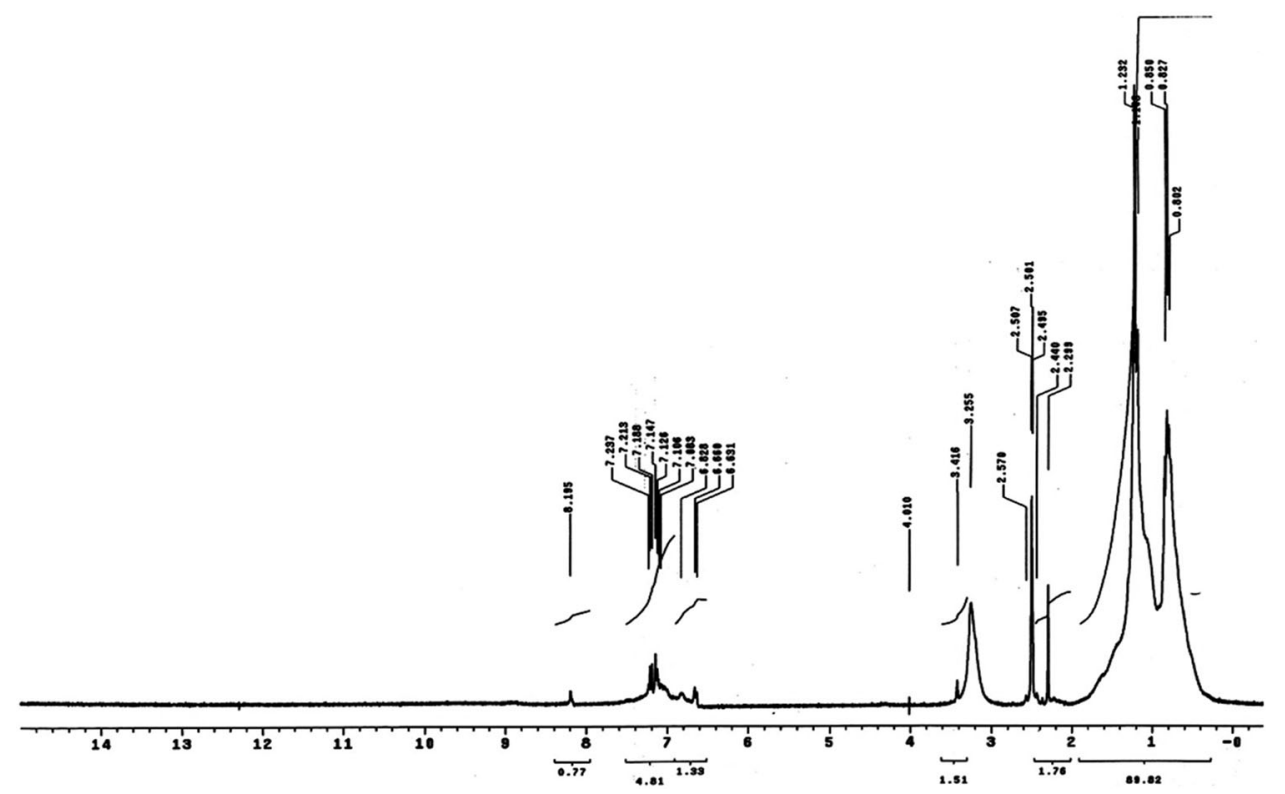

Preparation of mixtures of neutral sulfurized dodecyl phenate with dodecyl benzene sulfonic acid

The different mixtures $(X, Y, Z)$ were prepared using different ratio of neutral sulfurized dodecyl phenate with dodecyl benzene sulfonic acid (0.075: 0.025, 0.05: 0.05 , and 0.025: 0.075) moles, respectively. The prepared mixtures $(X, Y, Z)$ were mixed with different amounts of calcium hydroxide to prepare basic and overbasic mixtures where $X_{1}, X_{2}, Y_{1}, Y_{2}, Z_{1}, Z_{2}$ were 
Fig. $4 \mathrm{H}^{1} \mathrm{NMR}$ spectrum of product $\left(\mathrm{A}_{2}\right)$
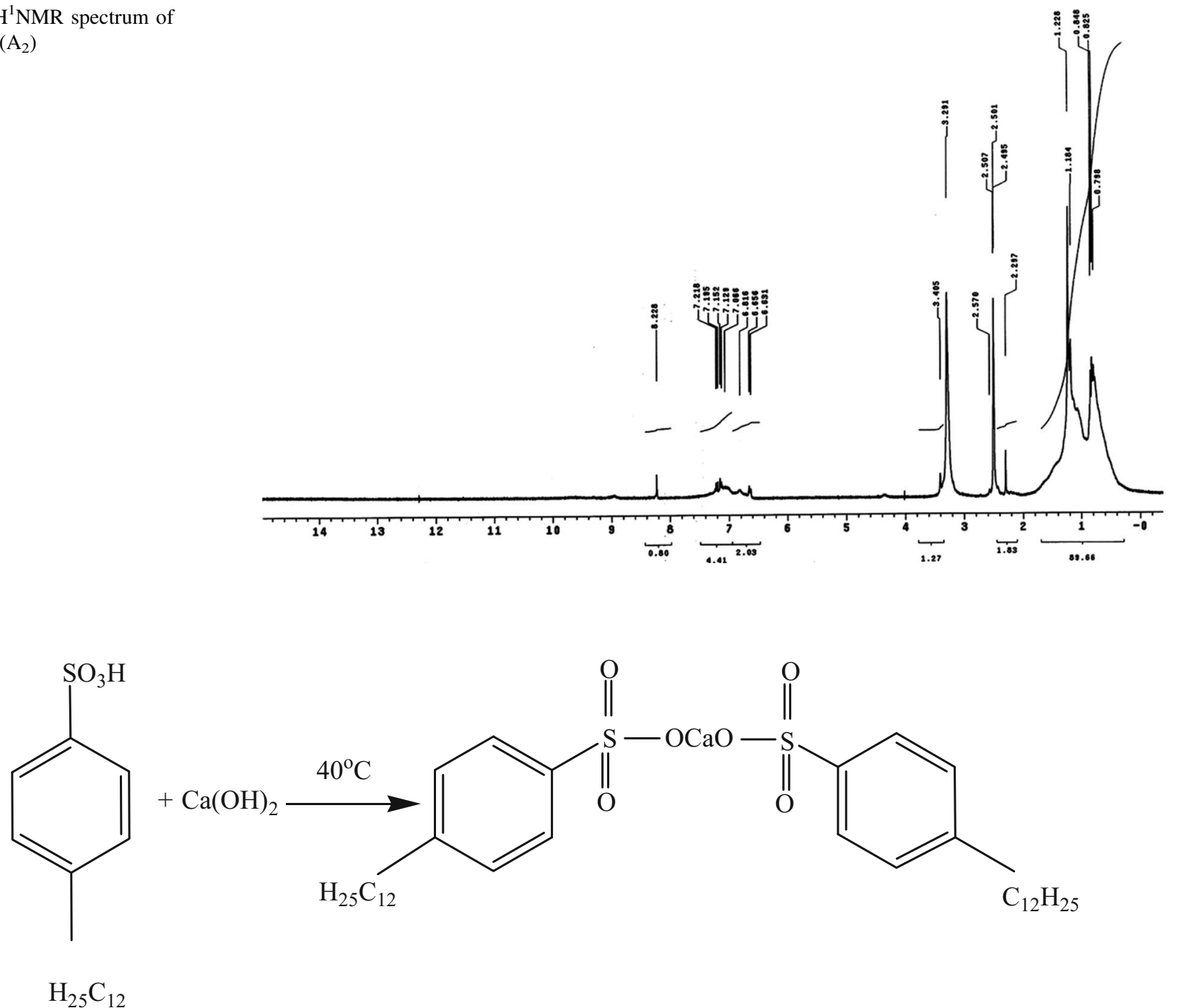

Scheme 4 Reaction of formation of neutral calcium dodecyl benzene sulfonate

obtained. The total base number TBN and calcium percentages of the prepared mixtures were measured and are listed in Table 3.

\section{Evaluation of the prepared compounds}

\section{As antioxidants}

All the prepared compounds were added to a sample of "SAE-30" lube oil free from any additives, in $2 \%$ concentration, and the blends obtained were subjected to serve oxidation condition as described previously and the oxidation stability expressed as increase in viscosity ratio $(\mathrm{V} /$ $\left.V_{0}\right)$ and total acid number $(\Delta \mathrm{TAN})$, and optical density $\left(\log I / I_{0}\right)$ that compared with lube oil sample free from additives. Oxidation stability results of lube oil without and with $2 \%$ wt additives of compound (A) after different oxidation hours are shown in Table 4.
Table 3 TBN and $\mathrm{Ca}$ wt\% results of the prepared mixtures

\begin{tabular}{lcl}
\hline Mixture & T.B.N & Ca wt $\%$ \\
\hline Mixture $X$ & 41.1 & 2.3 \\
Mixture $X_{1}$ & 111.11 & 4.1 \\
Mixture $X_{1}$ & 153 & 5.468 \\
Mixture $Y$ & 47.78 & 2.4 \\
Mixture $Y_{1}$ & 120 & 4.3 \\
Mixture $Y_{2}$ & 180 & 6.94 \\
Mixture $Z$ & 57 & 2.7 \\
Mixture $Z_{1}$ & 143.2 & 5.4 \\
Mixture $Z_{1}$ & 285 & 8.75 \\
\hline
\end{tabular}

It was found also that the additive prepared overbasic $\left(\mathrm{A}_{2}\right)$ are more efficient as antioxidant than other prepared additives. Increasing the proportions of metal in the phenate, increase their antioxidant properties and this may be attributed to the fact that excess base in the additives can 
Table 4 Oxidation stability of lube oil without and with $2 \%$ wt. additives of compound (A) after different oxidation hours

Table 5 Oxidation stability of lube oil without and with $2 \%$ wt. additives of compound (B) after different oxidation hours

\begin{tabular}{|c|c|c|c|c|c|c|c|c|c|c|c|c|}
\hline \multirow[t]{3}{*}{ Sample } & \multicolumn{4}{|c|}{$(\Delta \mathrm{TAN})$} & \multicolumn{4}{|c|}{$\left(V / V_{0}\right)$} & \multicolumn{4}{|c|}{$\log \left(I / I_{0}\right)$} \\
\hline & \multicolumn{4}{|c|}{ Time (h) } & \multicolumn{4}{|c|}{ Time (h) } & \multicolumn{4}{|c|}{ Time (h) } \\
\hline & 0 & 24 & 48 & 72 & 0 & 24 & 48 & 72 & 0 & 24 & 48 & 72 \\
\hline A & 0 & 0.94 & 1.49 & 3.57 & 1 & 1.06 & 1.11 & 1.2 & 0 & 0.02 & 0.055 & 0.06 \\
\hline $\mathrm{A}_{1}$ & 0 & 0.17 & 1.47 & 2.85 & 1 & 1.05 & 1.09 & 1.15 & 0 & 0.02 & 0.05 & 0.05 \\
\hline $\mathrm{A}_{2}$ & 0 & 0.15 & 1.02 & 1.52 & 1 & 1 & 1.1 & 1.1 & 0 & 0.01 & 0.03 & 0.02 \\
\hline Blank & 0 & 3.5 & 6.02 & 10.52 & 1 & 1.35 & 1.86 & 3.74 & 0 & 0.11 & 0.28 & 0.39 \\
\hline
\end{tabular}

\begin{tabular}{|c|c|c|c|c|c|c|c|c|c|c|c|c|}
\hline \multirow[t]{3}{*}{ Sample } & \multicolumn{4}{|c|}{$(\Delta \mathrm{TAN})$} & \multicolumn{4}{|c|}{$\left(V / V_{0}\right)$} & \multicolumn{4}{|c|}{$\log \left(I / I_{\mathrm{o}}\right)$} \\
\hline & \multicolumn{4}{|c|}{ Time (h) } & \multicolumn{4}{|c|}{ Time (h) } & \multicolumn{4}{|c|}{ Time (h) } \\
\hline & 0 & 24 & 48 & 72 & 0 & 24 & 48 & 72 & 0 & 24 & 48 & 72 \\
\hline$B$ & 0 & 0.95 & 1.29 & 2.5 & 1 & 1.07 & 1.07 & 0.9 & 0 & 0.03 & 0.16 & 0.3 \\
\hline Blank & 0 & 3.5 & 6.02 & 10.52 & 1 & 1.35 & 1.86 & 3.74 & 0 & 0.11 & 0.28 & 0.39 \\
\hline
\end{tabular}

neutralize the excess of acids formed during oxidation of lubricating oil [22]. Oxidation stability results of lube oil without and with $2 \%$ wt additives of compound (B) after different oxidation hours are shown in Table 5.

It is clear that calcium salt of dodecyl benzene sulfonate gives better results in oxidation stability test.

\section{As detergents/dispersants}

Spot method All the prepared compounds have been added to the oil samples in the concentration of $2 \% \mathrm{wt}$, and using spot test method results given in Table 6 show clearly that the prepared compounds have very good and excellent dispersion power (80-95\%) for sludge and solid particles formed during lube oil oxidation compared with lube oil only.

Results obtained in Table 6 shows that addition of different additives raise the dispersion of oil from $32 \%$ to approximately $95 \%$, this is because addition of the additive reduces the oxidation of lube oil and therefore reduces the formation of insoluble materials [23], disperses solid particles, and prevents their agglomeration so addition of these additives gave better oil dispersion.

It is clear from the data given here that excess base not only increase the power of phenate to neutralize the corrosive acids but also improve their efficiency as detergent/ dispersant additives. The increase in the proportion of calcium expressed in moles calcium hydroxide per mole dodecyl phenol increases detergency and dispersancy. This proportion results in the formation of an additive having a weight percentage of (8.54) for calcium and a total base number (TBN) of about (277.9) for the final additive $\left(\mathrm{A}_{2}\right)$. It is clear from the data given here that excess base not only increases the power of phenate to neutralize the corrosive
Table 6 Percentage of dispersion in the lube oil sample and it blends with the prepared additives $\left(A, A_{1}, A_{2}, B\right)$

\begin{tabular}{llll}
\hline Sample & \multicolumn{3}{l}{ Percentage of dispersion, Time $(\mathrm{h})$} \\
\cline { 2 - 4 } & 24 & 48 & 72 \\
\hline Blank & 35 & 33 & 32 \\
$\mathrm{~A}$ & 90 & 95 & 90 \\
$\mathrm{~A}_{1}$ & 92 & 89 & 94 \\
$\mathrm{~A}_{2}$ & 90 & 90 & 95 \\
$\mathrm{~B}$ & 90 & 78 & 85 \\
\hline
\end{tabular}

acids but also improves their efficiency as detergent/dispersant additives.

Determination of sludge The percentages of sludge formation during the oxidation of lube oil sample with and without additive are determined and the data are given in Table 7 and confirms that the presence of this additive decreases the percentage of sludge formed to $1.5 \% \mathrm{com}$ pared to $6.6776 \%$ for the oil free from any additive as they reduce oil oxidation and this decreases the formation of small amounts of asphaltic substances, which after that leads to sludge formation. The lowest sludge percentage formed in case of addition of additive $\left(\mathrm{A}_{2}\right)$ equals 0.13 .

Determination of the potential detergent dispersant effciency (PDDE) The results obtained from the prepared additive $\left(\mathrm{A}, \mathrm{A}_{1}, \mathrm{~A}_{2}, \mathrm{~B}\right)$ are shown in Table 8 which indicate that additive $\left(\mathrm{A}_{2}\right)$ has good efficiency as detergent/ dispersant additive which is $91.11 \%$ compared to $53.78 \%$ for the blank as the additive reduces oil oxidation and hence prevents precipitant agglomeration. 
Table 7 The percentages of sludge formation during the oxidation of lube oil sample without and with additive (A, $\left.\mathrm{A}_{1}, \mathrm{~A}_{2}, \mathrm{~B}\right)$

Table 8 The percentages of PDDE during the oxidation of lube oil sample without and with additive (A)

\begin{tabular}{ll}
\hline Sample & \% of sludge \\
\hline $\mathrm{A}$ & 1.5 \\
$\mathrm{~A}_{1}$ & 0.91 \\
$\mathrm{~A}_{2}$ & 0.13 \\
$\mathrm{~B}$ & 1.5 \\
Blank & 6.6776 \\
\hline
\end{tabular}

\begin{tabular}{ll}
\hline Sample & \% of PDDE \\
\hline $\mathrm{A}$ & 77 \\
$\mathrm{~A}_{1}$ & 89 \\
$\mathrm{~A}_{2}$ & 91.11 \\
$\mathrm{~B}$ & 84.52 \\
Blank & 53.78 \\
\hline
\end{tabular}

\section{Evaluation of the prepared neutral, basic,} and overbasic mixtures $(X, Y, Z)$

\section{As antioxidants}

Oxidation stability results of lube oil without and with $2 \%$ wt additives of groups $(X, Y, Z)$ after different oxidation hours are shown in Figs. 5, 6, 7, 8, 9, 10, 11, 12, and 13; this indicated that all the prepared compounds impart better oxidation resistance properties to the lube oil compared with the undoped oil. Mix $(Z)_{2}$ with TBN equals to (285) and percentage of calcium equals to (8.75) and higher ratio of dodecyl benzene sulfonic acid imparts better oxidation resistance properties to the lube oil, the efficiency increases with the increase in sulfonic acid ratio in mixture as sulfonic group is more electronegative than phenolic group, which makes donation of labile hydrogen better to stabilize the chain radicals; i.e., these inhibitors destroy the peroxide radicals and thus, stop the propagation step and convert highly reactive peroxide radicals to more stable compounds.

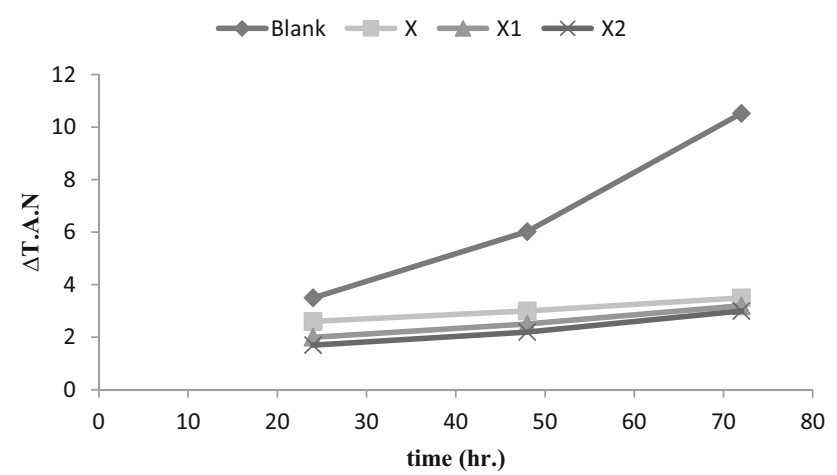

Fig. 5 Variation of $\triangle$ TAN with oxidation time of lube oil without and with additives $\left(X, X_{1}\right.$, and $\left.X_{2}\right)$

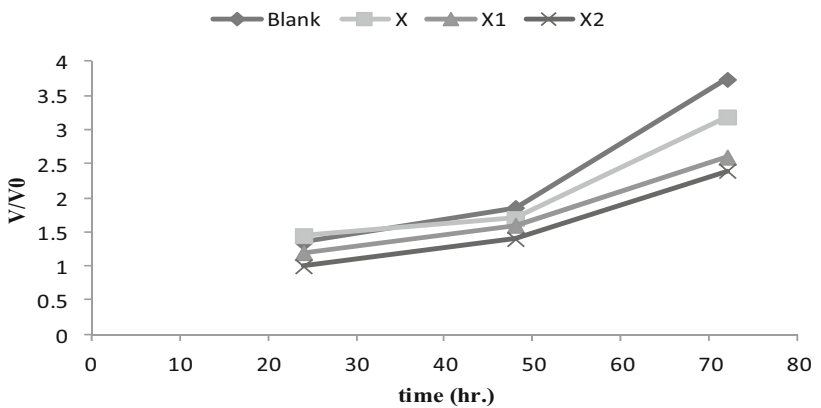

Fig. 6 Variation of $V / V_{0}$ with oxidation time of lube oil without and with additives $\left(X, X_{1}\right.$, and $\left.X_{2}\right)$

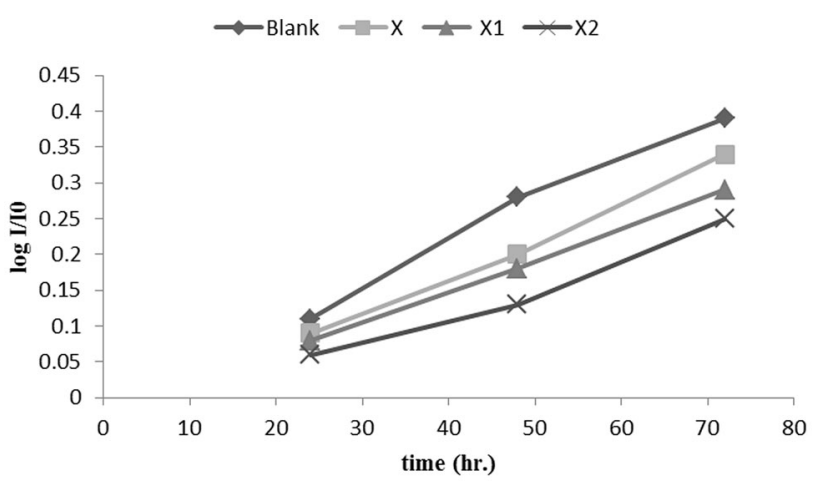

Fig. 7 Variation of $\log \mathrm{I} / \mathrm{I}_{\mathrm{o}}$ with oxidation time of lube oil without and with additives $\left(X, X_{1}\right.$, and $\left.X_{2}\right)$

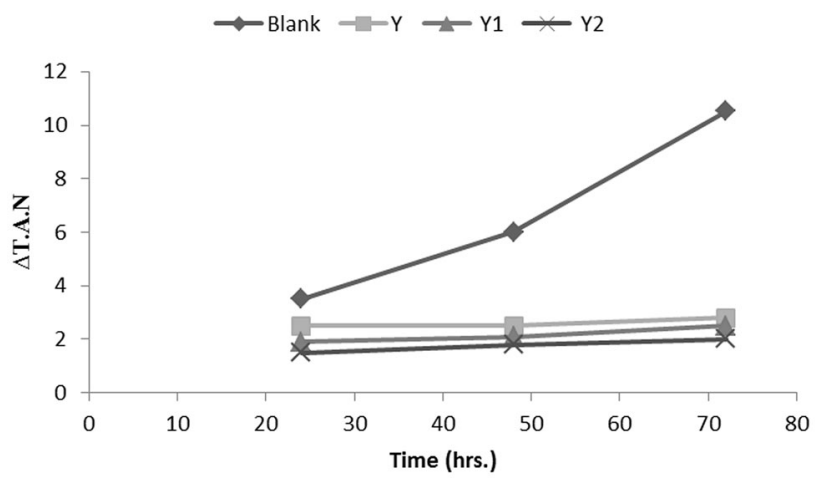

Fig. 8 Variation of $\triangle \mathrm{TAN}$ with oxidation time of lube oil without and with additives $\left(Y, Y_{1}\right.$, and $\left.Y_{2}\right)$

\section{As detergents/dispersants}

Spot method The results given in Table 9 show clearly that the prepared additives have very good to excellent dispersancy power (70-97\%) for the sludge and soil particles formed during lube oil oxidation compared with the lube oil only. It is clear that the addition of these compounds not only disperses solid particles in the oil and thus prevents their agglomeration and precipitation on metallic parts of engines that can cause damage, but also neutralizes some of the acidic products of oxidation due to their basic 


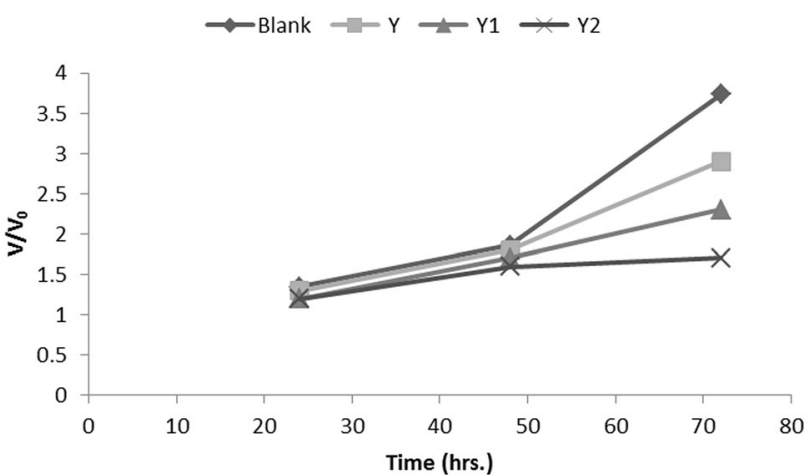

Fig. 9 Variation of $V / V_{0}$ with oxidation time of lube oil without and with additives $\left(Y, Y_{1}\right.$, and $\left.Y_{2}\right)$

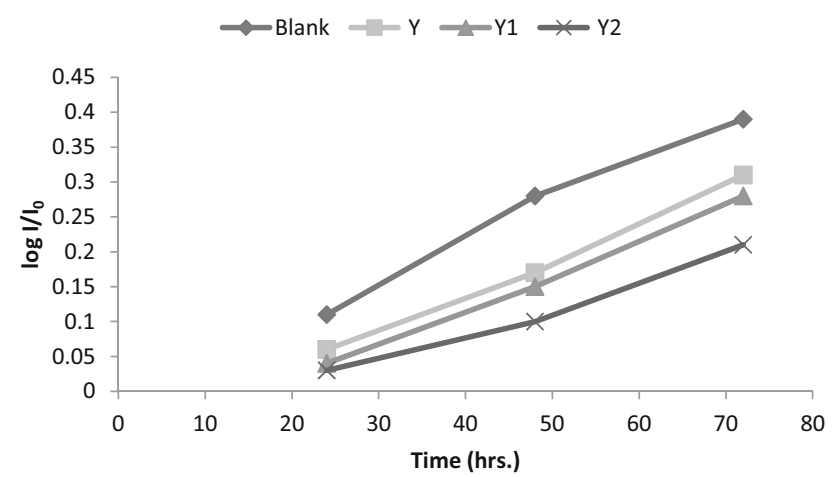

Fig. 10 Variation of $\log I / I_{0}$ with oxidation time of lube oil without and with additives $\left(Y, Y_{1}\right.$, and $\left.Y_{2}\right)$

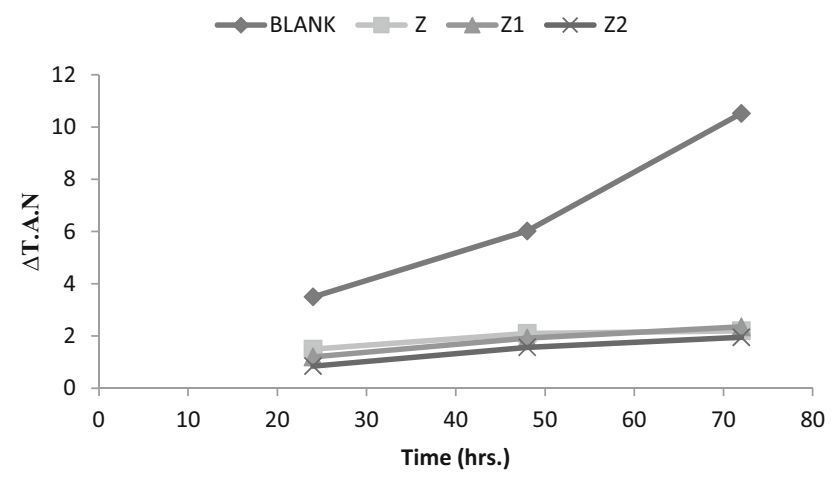

Fig. 11 Variation of $\triangle \mathrm{TAN}$ with oxidation time of lube oil without and with additives $\left(Z, Z_{1}\right.$, and $\left.{ }_{2}\right)$

nature. The efficiency of additive as detergent increases by increasing the basicity of the prepared additives.

Determination of sludge The percentages of sludge formation during the oxidation of lube oil sample with and without additives are determined and the data are given in Table 10. It was found that mixture $(Z)_{2}$ gives lower quantity of sludge; this is may be due to increasing of the proportion of metal, which increases their antioxidant properties and this may be attributed to the fact that excess

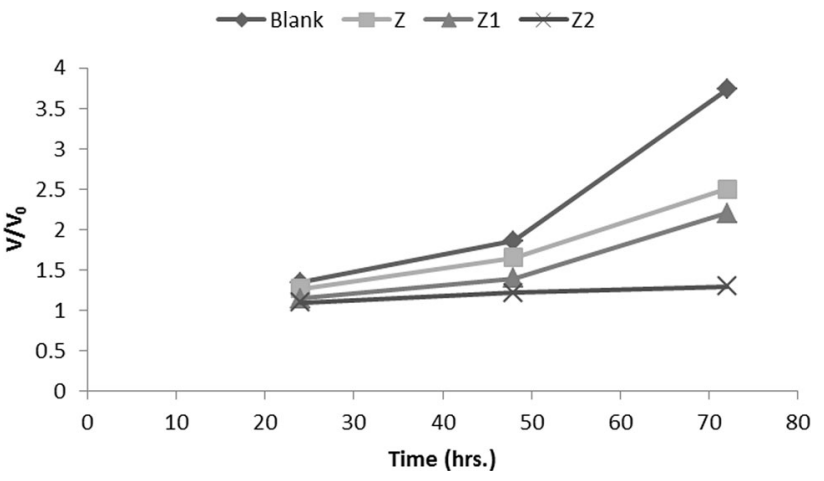

Fig. 12 Variation of $V / V_{0}$ with oxidation time of lube oil without and with additives $\left(Z, Z_{1}\right.$, and $\left.Z_{2}\right)$

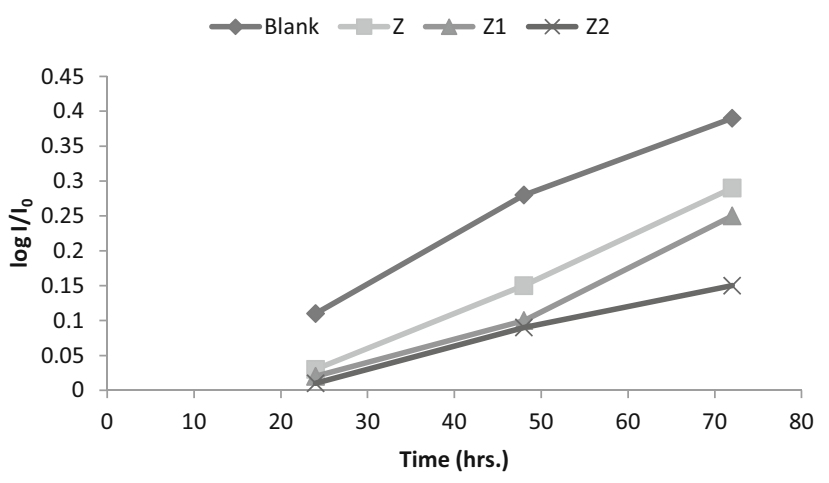

Fig. 13 Variation of $\log I / I_{0}$ with oxidation time of lube oil without and with additives $\left(Z, Z_{1}\right.$, and $\left.Z_{2}\right)$

Table 9 Percentage of dispersion of the lube oil sample and it is blends with the prepared additives

\begin{tabular}{llcl}
\hline Sample & \multicolumn{3}{l}{ Percentage of dispersion, Time $(\mathrm{h})$} \\
\cline { 2 - 4 } & 24 & 48 & 72 \\
\hline Blank & 35 & 33 & 32 \\
Mixture $X$ & 75 & 83 & 80 \\
Mixture $X_{1}$ & 92 & 85 & 84 \\
Mixture $X_{2}$ & 95 & 91 & 90 \\
Mixture $Y$ & 71 & 86 & 82 \\
Mixture $Y_{1}$ & 97 & 87 & 86 \\
Mixture $Y_{2}$ & 97 & 93 & 93 \\
Mixture $Z$ & 91 & 90 & 90 \\
Mixture $Z_{1}$ & 95 & 90 & 92 \\
Mixture $Z_{2}$ & 97 & 94 & 97 \\
\hline
\end{tabular}

base in the additives neutralization of excess acids formed during oxidation of lubricating oil.

Determination the potential detergent dispersant efficiency $(P D D E)$ The results obtained from the prepared additives $\left[\left(X-X_{2}\right),\left(Y-Y_{2}\right)\right.$, and $\left.\left(Z-Z_{2}\right)\right]$ are shown in Table 11. 
Table 10 The percentages of sludge formation during the oxidation of lube oil sample without and with mixture additives

Table 11 The percentages of PDDE during the oxidation of lube oil sample without and with mixture additives

\begin{tabular}{ll}
\hline Sample & \% of sludge \\
\hline Blank & 6.6776 \\
Mixture $X$ & 2.5 \\
Mixture $X_{1}$ & 0.89 \\
Mixture $X_{2}$ & 0.75 \\
Mixture $Y$ & 2.1 \\
Mixture $Y_{1}$ & 0.7 \\
Mixture $Y_{2}$ & 0.95 \\
Mixture $Z$ & 1.22 \\
Mixture $Z_{1}$ & 0.64 \\
Mixture $Z_{2}$ & 0.14 \\
\hline
\end{tabular}

\begin{tabular}{ll}
\hline Sample & \% of PDDE \\
\hline Blank & 53.78 \\
Mixture $X$ & 75 \\
Mixture $X_{1}$ & 80 \\
Mixture $X_{2}$ & 82 \\
Mixture $Y$ & 75 \\
Mixture $Y_{1}$ & 82 \\
Mixture $Y_{2}$ & 85 \\
Mixture $Z$ & 78 \\
Mixture $Z_{1}$ & 87 \\
Mixture $Z_{2}$ & 90 \\
\hline
\end{tabular}

\section{Conclusion}

The conclusions could be derived from the results of this study that:

- Neutral, basic, and overbasic calcium salt of sulfurized dodecyl phenol were prepared.

- Neutral calcium salt of dodecyl benzene sulfonic acid was prepared.

- Three neutral mixtures were prepared by mixing neutral calcium salt of dodecyl phenol and dodecyl benzene sulfonic acid with different ratios (0.075: 0.025, 0.05: 0.05, and 0.025: 0.075).

- Basic and overbasic salts of the neutral compounds were prepared using different ratios of calcium hydroxide and carbon dioxide.

- All the prepared compounds are soluble in lubricating oil (SAE 30).

- The efficiency of the prepared compounds as lube oil additives (antioxidants and detergents/dispersants) was studied. It was found that all the prepared additives have excellent power of dispersion and detergency.

- It was found that the efficiency of the prepared compounds as antioxidants increases with increasing its basicity.
- It was also found that the (detergent/dispersant and antioxidant) efficiency of the prepared mixtures increases by increasing the dodecyl benzene sulfonic acid ratio and by increasing the percentage of calcium salt.

Open Access This article is distributed under the terms of the Creative Commons Attribution 4.0 International License (http://crea tivecommons.org/licenses/by/4.0/), which permits unrestricted use, distribution, and reproduction in any medium, provided you give appropriate credit to the original author(s) and the source, provide a link to the Creative Commons license, and indicate if changes were made.

\section{References}

1. leksandar D, Dobromir T, Petko P (2012) Obtained and investigation of the ecological film-forming anticorrosion oil composition(FAOC), reducing oil consumption during exploitation. Pet Coal 54:114-119

2. Igartua A, Nevshupa R, Feruandez X, Conte M, Zabala R, Bernaula J, Zabala P, Luther R, Rausch J (2011) Alternative ecofriendly lubes for clean two-stroke engines. Tribol Int 44:727-736

3. Amal MN, Nehal SA, Hamdy SA, Ahmed FK (2016) Synthesis and utilization of non-metallic detergent/dispersant and antioxidant additives for lubricating engine oil. Tribol Int 93:297-305

4. Pingping Y, Xiaoxia J, Shu L, Shizhuo L (2002) Preparation of $\mathrm{NiMoO}_{2} \mathrm{~S}_{2}$ nano particle and investigation of its tribological behavior as additive in lubricating oils. Wear 253:572-575

5. Vibhu S, Ali E, Pranesh BA (2015) Analytical study of tribofilms generated by the interaction of ashless antiwear additives with ZDDP using XANES and nano-indentation. Tribol Int 82:43-57

6. Waston S (2010) Lubricant-derived ash-in-engine sources and opportunities for reduction. PhD. Thesis, Massachusetts Institute of technology, pp 35-36

7. Dairo C, Massimiliano DA, Nicolo V (2012) Influence of tightening procedures and lubrication conditions on titanium screw joints for lightweight applications. Tribol Int 55:68-76

8. Nehal SA, Amal MN, Rabab MN, Manar AR, Ahmed FK (2014) Novel terpolymers as pour point depressants and viscosity Modifiers for lube oil. Pet Sci Technol 32:680-687

9. Nehal SA, Amal MN, Yasser KA, Reham IS (2014) Preparation, characterization and evaluation of some metallic lube oil additives. IOSR JAC 7:56-67

10. Hugh S (2008) Low-and zero-sulphated ash, phosphorous and sulfur anti-wear additives for engine oils. Lubr Sci 20:103-136

11. Anand KT, Ravikrishnan V (2015) Characterization of thermal stability of synthetic and semi-synthetic engine oils. Lubr. 3:54-79

12. Nehal SA, Hamdy SA, Ahmed FE, Amal MN (2015) Synthesis and evaluation of ashless detergent/dispersant additives for lubricating engine oil. Tribol. 67:622-629

13. Morizur MF, Teysset O (1992) Antiwear actions of additives in solid dispersion. Lubr Sci 4:277-299

14. Najman M, Kasrai M, Bancroft GM, Davidson R (2006) Combination of ashless antiwear additives with metallic detergents: interactions with neutral and overbased calcium sulfonates. Tribol Int 39:342-355

15. Cizaire L, Martin JM, Le Mogne Th, Gresser E (2004) Chemical analysis of overbased calcium sulfonate detergents by coupling XPS, ToF-SIMS, XANES, and EFTEM. Colsurfa 238:151-158 
16. Jao TC, Esche CK, Black ED and Jenkins RH (1978) Process for preparing over-based sulfurized alkaline earth metal phenates. US patent 4123371

17. Jao TC, Esche CK, Black ED and Jenkins RH (1991) Process for the preparing of sulfurized overbased phenate detergents. E. P. Patent 0417962A1

18. Lamb GG, Loance CM, Gaynor JW (1941) Indiana stirring oxidation test for lubricating oils. Ind Eng Chem Res 13:317-321

19. Gates V. A., Bergstrom R. F.and Wendt L. A. (1955) Further discussion on "oil spot" evaluation of used engine lubricants. S. A. E. paper 550126

20. Rubinshtein IA, Popova EA, Novosartov GT (1979) Method for determination of sludge formed during operation or storage of synthetic lube oils. Chem Technol Fuels Oil 15:223-225
21. Jenő H, Márk B, Ádám B, Jenő B (2008) Development of multifunctional additives based on vegetable oils for high quality diesel and biodiesel. Chem Eng Res Des 86:793-799

22. Maayta AK, Fares MM, Al-Shawabkeh AF (2010) Influence of linear alkyl benzene sulphonate on corrosion of iron in presence of magnetic field: kinetic and thermodynamic parameters. Int $\mathbf{J}$ Corros 2010:1-9

23. Nehal S. A.(1993) Studies on Some Lube Oil Additives nased on Mannich bases. M.Sc. Thesis, Ain Shams University, Cairo, Egypt 